\title{
Exploring Website Preferences for African American Women: An Evaluation of an Internet-Based Source of Health Information on Eating Healthy and Being Active
}

\author{
Naa-Solo Tettey ${ }^{1} \&$ Barbara Wallace ${ }^{2}$ \\ ${ }^{1}$ Public Health Department, William Paterson University, Wayne, NJ, USA \\ ${ }^{2}$ Department of Health and Behavior Studies, Columbia University, Teachers College, New York, NY, USA \\ Correspondence: Naa-Solo Tettey, Public Health Department, William Paterson University, Wayne, NJ, 300 \\ Pompton Road, University Hall, Suite 359, Wayne, NJ 07470, USA. Tel: 703-720-2604. E-mail: \\ tetteyn@wpunj.edu
}

\author{
Received: January 1, 2019 Accepted: January 31, 2019 Online Published: April 8, 2019 \\ doi:10.5539/gjhs.v11n5p59 URL: https://doi.org/10.5539/gjhs.v11n5p59
}

\begin{abstract}
Introduction: Internet-based health interventions continue to be popular and effective, and one area of focus of such interventions is weight loss. Although African-American women are regular users of Internet-based health interventions, there is a dearth of research regarding Internet usage and website preferences of this group. The purpose of this study was to explore the relationship between website attributes that influence African American women to use health-related websites, their stage of change for using the Internet to access information on health care, and predictor variables for website ratings.

Methods: The study used a backwards stepwise regression analysis to determine the best predictor of high ratings of the Eat Healthy - Be Active web portal and the Rating and Evaluating Health Care Websites Survey to measure website attitudes and beliefs and stage of change for using the computer and Internet to access health care information. The participants were 206 African American women who use the Internet.

Results: The regression analysis indicated that the predictor variables were education level, BMI, and weight.

Conclusion: This study demonstrates that various factors influence the effectiveness of Internet-based interventions targeted at African-American women. Future research should continue to explore these factors, particularly for groups with higher rates of preventable diseases.
\end{abstract}

Keywords: African American women, health disparities, internet health, website preferences, obesity, health communication

\section{Introduction}

Obesity is a public health problem that has reached epidemic proportions (Bleich, Bennett, Gudzune, \& Cooper, 2012). It affects over $35 \%$ of all adults and $17 \%$ of all children in the United States (Bleich et al., 2012; Ogden, Carroll, Kit, \& Flegal, 2014) and crosses age, gender, class, and racial/ethnic lines (Wright \& Aronne, 2012). Healthy People 2020, a set of national objectives designed to increase quality and longevity of life and to eliminate health disparities, includes obesity as one of the leading causes of preventable death in the United States (U.S. Department of Health and Human Services, 2015).

The group with the highest rates of obesity in the United States is African American women (Sira \& Pawlak, 2012). Public health researchers are trying to understand why there is such a disparity in obesity rates between this demographic and others. What is understood is that various factors contribute to weight-related problems and the higher prevalence of obesity in African American women. First, body-type ideals for African American women show a preference for more weight (Sira \& Pawlak, 2012). Second, poor and minority communities have fewer supermarkets and health food stores than do more affluent communities; hence, members of these communities are more likely to shop in local corner stores or bodegas that carry unhealthy processed foods that are higher in fat and sugar (Kirby, Liang, Chen, \& Wang, 2012). Finally, low health literacy also contributes to higher rates of obesity in African American women (U.S. Department of Health and Human Services, 2010).

The most effective programs for weight loss have been those that involve weekly clinic visits (Kodama et al., 
2012). However, these programs tend to be time consuming and impractical (Kodama et al., 2012). Thus, weight-loss/obesity prevention intervention approaches that are Internet-based have gained popularity in recent years (Kodama et al., 2012; Patrick et al., 2011). With greater numbers of individuals' gaining access to the Internet, such programs have become a viable means for delivering public health interventions (Kodama et al., 2012; Adewuyi \& Adefemi, 2016).

Community-based interventions have been shown to be effective in addressing public health issues in the United States, and the use of technology to improve health has become important in this effort (Kodama et al., 2012; Patrick et al., 2011; Bravender et al., 2013; Tate, Wing, \& Winett, 2013). Internet-based health programs have grown in popularity because they reduce delivery costs, are more convenient to users, can be provided in a more timely manner, reduce stigma, increase control of the intervention, and reduce geographic, time, and mobility-based barriers and, as such, provide opportunities for obesity prevention interventions (Kodama et al., 2012; Patrick et al., 2011). Currently, the Internet serves several purposes in the field of health care, including providing health information (Skranes, Lohaugen, \& Skranes, 2015), creating web-based health support groups (Bravender et al., 2013), and facilitating online pharmaceutical purchases (Skranes, Lohaugen, \& Skranes, 2015). Computer-tailored interventions have been used since the 1990s to promote healthy eating behaviors and for promoting weight loss (Kodama et al., 2012; Patrick et al., 2011; Ling \& Mengjun, 2013; Springvloet, Lechner, de Vries H, Candel, \& Oenema, 2015).

Notably, the Internet has great potential for providing such programs to lower income and minority populations (Cavallo et al., 2012). African American Internet users, however, may have a different set of needs and interests, as compared to other minority populations, that must be taken into consideration (Wilson, Alia, Kitzman-Ulrich, \& Resnicow, 2014; Pew Research Center, 2017). Messages regarding health behavior changes are most effective with African American audiences when these messages, particularly those delivered through the Internet, are tailored to their needs and capabilities (Bennett et al., 2014).

Practitioners must be able to use this medium effectively to reduce obesity rates among African American women. To this end, the factors that serve as motivators for African American women to utilize an Internet site for health reasons must be established. Hence, the purpose of this study was to determine the predictors of a positive rating for a weight management website as perceived by African American women. Another aim was to determine these women's attitudes and beliefs about what they value in websites and how these attitudes and beliefs relate to their stage of change and to using the Internet to access health care information, in general, and healthy eating and physical activity information, in particular.

\subsection{Theoretical Framework: The Transtheoretical Model}

The theoretical framework for this study is the transtheoretical model, developed by Prochaska and DiClemente (Cancer Prevention Research Center, 2010). The transtheoretical model, also known as the stages of change theory, concerns how people modify a problem behavior or acquire a positive behavior (Cancer Prevention Research Center, 2010). According to this model, change is a process that involves progression through five stages: pre-contemplation, contemplation, preparation, action, and maintenance (Cancer Prevention Research Center, 2010). The stages of change theory has been found to be helpful in the design, delivery, and evaluation of interventions to help people to adopt healthy behaviors (Norcross, Krebs, \& Prochaska, 2011; West et al., 2013). When the model is used correctly, the intervention developer can assess an individual's current stage of change to develop an intervention that will help to move that individual through successive stages (Norcross, Krebs, \& Prochaska, 2011; West et al., 2013; Mastellos, Gunn, Felix, Car, \& Majeed, 2013). Applying the stages of change model to change dietary behaviors can help to identify the types of interventions that are most effective at each stage of change (West et al., 2013; Mastellos, Gunn, Felix, Car, \& Majeed, 2013; Glanz, Patterson, Kristal, DiClemente, Heimendinger, Linnan, \& McLerran, 1994). In this study, the stages of change theory provided a guide for identifying the significant behaviors and attributes that website users exhibit during the adoption of a new technology (e.g. using health information websites). Specifically, the stage of change model was used to identify the progression or changes in the behavior and attitudes of African American women who used a health information website.

\section{Methods}

Divahealth.org, specifically, Donna Bacon, Ed.D.; Barbara Wallace, Ph.D.; and Rupananda Misra, created the D.I.V.A.S (Developing Individual Attitudes Values and Skills) website (www.DIVAhealth.org). The website, launched in 2007, was designed to educate and empower women, especially young African American women, with regard to improving their health. The website provides women with information about a variety of health issues through the use of a simple design with limited technological enhancements. 
The authors of the current study expanded the D.I.V.A.S website by adding a section/portal that is dedicated to obesity prevention, which provides information on nutrition, physical activity, and weight loss (Eat Healthy, Be Active; http://www.divahealth.org/EatHealthy/BeActive/index.html). The purpose of this expansion was twofold: (1) to provide the www.DIVAhealth.org website with new section/portal that aims to meet the needs of African American women at risk for obesity, overweight, poor nutrition, low physical activity, and the health outcomes associated with these risk factors by providing information and education on these topics; and (2) to host a survey designed to ascertain women's multiple personal-level variables (e.g., health status, engagement in healthy living behaviors, perception of neighborhood safety factors that affect their physical activity, computer/Internet access, attitudes and beliefs about what they value in websites, self-efficacy in using health care websites, stage of change for using computers/Internet for accessing health care websites), and their rating of the new website portal as well as to obtain their responses to and recommendations for improving the new portal. The evaluation of the new section/portal enables an understanding of what these women find most effective in an online weight-loss/physical activity website designed to address their needs.

A convenience sample of 206 African American women who use the Internet was used for this study. Participants were recruited through a social marketing campaign that included a snowballing technique based on word-of-mouth communication and social networking technology; the posting of flyers in community settings that members of the target population tend to frequent; e-mails, text-messaging, and postings on websites or website bulletin boards; online classified advertisements; and the social media websites Twitter and Facebook.

The researcher determined the relationship between participant personal-level variables and the website attitudes and beliefs (WAB-10) portion of the Rating and Evaluating Health Care Websites Survey (REHWS-74) (Tettey, 2010). The WAB-10 contains 10 items that are used to assess attitudes and beliefs about what constitutes good website design, including a website's use of color, pictures of people, and social interactive opportunities. The WAB-10 is Likert-scaled ( 1 = strongly disagree, $10=$ strongly agree), with higher scores' indicating higher ratings. The scale also generates a global score, which is a sum of all ratings.

The stage of change for using the computer and Internet to access health care information (SOCCIAHCI-7) scale also was used (Tettey, 2010). This scale is drawn from the REHWS-74, with minor modifications made specific to obtaining information on healthy eating and being physically active (the original scale contained items in regard to HIV/AIDS). Like the original scale, the present scale still has six items to assess stage of change for various Internet-based activities (e.g., getting information, visiting support groups). The scale also generates a global score, which is a sum of the scores for all six items.

Participants used SurveyMonkey, an online survey service, to complete the survey questionnaire. Participants' successfully accessing and completing the survey established that they knew how to use the Internet and its basic functions. The survey tool included the IRB-approved research description, informed consent, and a statement of participants' rights. The tool included an opportunity to provide an electronic signature, indicating informed consent, after which participants proceeded to the main survey questionnaire.

The data analyses, using SPSS, utilized both inferential and descriptive statistics. The Pearson correlation coefficient was used to determine the relationship between variables. To determine the internal consistency of the measures, the researcher used Cronbach's alpha, which was a measure of how closely items are related to each other (Tavakol \& Dennick, 2011) and, hence, a measure of scale reliability (Tavakol \& Dennick, 2011). A backward stepwise regression, which included all predictor variables that were significant at the $p=.05$ level in the bivariate analyses, was performed to determine the significant predictors of high ratings of the portal.

\section{Results}

A total of 265 respondents began the survey; of these, 206 completed the survey in their entirety, resulting in an $80.2 \%$ response rate. The demographics of participants are presented in Table 1 . 
Table 1. Demographic Characteristics $(\mathrm{N}=206)$

\begin{tabular}{|c|c|c|}
\hline Characteristic & $n$ & $\%$ \\
\hline \multicolumn{3}{|l|}{ Age } \\
\hline $18-30$ years & 85 & 41.3 \\
\hline $31-40$ years & 59 & 28.6 \\
\hline $41-50$ years & 47 & 22.8 \\
\hline $51-60$ years & 11 & 5.3 \\
\hline $61+$ years & 4 & 1.9 \\
\hline \multicolumn{3}{|l|}{ Education } \\
\hline High School/GED & 34 & 16.5 \\
\hline Associate's & 48 & 23.3 \\
\hline Bachelor's & 73 & 35.4 \\
\hline Graduate & 51 & 24.8 \\
\hline \multicolumn{3}{|l|}{ Religious Involvement } \\
\hline None & 24 & 11.7 \\
\hline Low & 50 & 24.3 \\
\hline Moderate & 74 & 35.9 \\
\hline High & 58 & 28.2 \\
\hline \multicolumn{3}{|l|}{ Marital Status } \\
\hline Partner (No) & 135 & 65.5 \\
\hline Married (Yes) & 71 & 34.5 \\
\hline \multicolumn{3}{|l|}{ Country of Birth } \\
\hline Born in the United States & 169 & 82 \\
\hline Foreign-born & 37 & 18 \\
\hline \multicolumn{3}{|l|}{ Employment } \\
\hline Employed & 74 & 35.9 \\
\hline Unemployed & 132 & 64.1 \\
\hline
\end{tabular}

Reliability of the data was determined using Cronbach's alpha. The WAB-10 had a Cronbach's alpha of .910 for all 10 items, indicating very good internal consistency. The SOCCIAHCI-7 had a Cronbach's alpha of .922 for all seven items, also indicative of very good internal consistency.

As noted, backward stepwise regression was performed for this analysis to determine the significant predictors of high ratings of the portal, the first objective of the study. The regression began with a number of models, and the variables that were least significant were excluded until the significant predictors remained. The regression analysis indicated that the predictor variables were education level, body mass index, and self-perceived weight. The adjusted $R^{2}$ for this model was .091, which indicates that, for the full model with all variables entered, $9.1 \%$ of the variance is explained by these three variables. Those who rated the portal more favorably were less educated $(B$ $=-.248, S E=.110, p=.026)$; were heavier, based on self-perception $(B=.392, S E=.141, p=.006)$, and scored higher on the WAB-10; i.e., they rated website features as more important $(B=.144, S E=.061, p=.020)$.

WAB-10 scores were used to determine attitudes and beliefs about what participants value in websites, the second objective of the study. The item with the highest mean $(8.95, S D=1.45)$ was Item 3, "Important for websites to be easy to read." "Strongly agree" was chosen by $61.2 \%$ of participants $(n=126)$. The second highest rating was for Item 1, "Important for websites to have direct links to the information that I need, so I can get to it quickly," with a mean of $8.93(S D=1.84)$. This item was rated at the highest level, 10 ("strongly agree"), by $61.2 \%$ of the women $(n=126)$. The least important attribute, "Have a talking voice" (Item 9) had a mean of $5.37(S D=3.04)$, with only $18 \%$ of participants $(n=37)$ who chose "strongly agree." 
To determine correlation between scores on the WAB-10 and the SOCCIAHCI-7, Pearson correlations were used. There was a positive relationship between high stage of change for accessing health care information, specifically, to share information with others (e.g., family, friends, students, clients) (Item 4), and high website attitudes and beliefs (e.g., rating web features as highly important) $(r=.196, p=.005)$. There was a weaker, yet significant, relationship between high stage of change for accessing health care information (Item 1) and high website attitudes and beliefs $(r=.149, p=.033)$. The complete results are presented in Table 2.

Table 2. Relationship between website attitudes and beliefs and the stage of change for using the computer and the internet to access health care information

\begin{tabular}{|c|c|c|c|}
\hline & \multicolumn{3}{|c|}{ Website Attitudes and Beliefs (Rating High) } \\
\hline & $\mathrm{N}$ & $\begin{array}{l}\text { Pearson } \\
\text { Correlation }\end{array}$ & $\begin{array}{l}\text { Sig. } \\
\text { (2-tailed) }\end{array}$ \\
\hline More advanced stage of change for computers and Internet & 206 & .149 & $.033 *$ \\
\hline $\begin{array}{l}\text { In terms of using the computer and Internet to access health } \\
\text { care information }\end{array}$ & 206 & .086 & .217 \\
\hline $\begin{array}{l}\text { In terms of using the computer and Internet to access health } \\
\text { care information, specially about prescription medications } \\
\text { and other remedies and treatments }\end{array}$ & 206 & .116 & .097 \\
\hline $\begin{array}{l}\text { In terms of using the computer and the Internet to access } \\
\text { health care information, specifically about my personal } \\
\text { medical conditions and health concerns }\end{array}$ & 206 & .126 & .071 \\
\hline $\begin{array}{l}\text { In terms of using the computer and the Internet to access } \\
\text { health care information, specifically to share information } \\
\text { with others (i.e., family, friends, etc.) }\end{array}$ & 206 & .196 & $.005 * *$ \\
\hline $\begin{array}{l}\text { In terms of using the computer and the Internet to access } \\
\text { health care information, specifically about physical activity } \\
\text { and exercise }\end{array}$ & 206 & .102 & .146 \\
\hline $\begin{array}{l}\text { In terms of using the computer and the Internet to access } \\
\text { health care information, specifically about nutrition and } \\
\text { healthy eating guidelines }\end{array}$ & 206 & .103 & .139 \\
\hline
\end{tabular}

\section{Discussion}

The findings of the present study add to the literature by suggesting that African American women can be effectively recruited for participation in Internet-based research using social marketing campaigns that rely on e-mails, text-messages, and social networking. Moreover, African American women in the sample demonstrated that the quality of computer and Internet access and self-efficacy for accessing Internet websites are necessary for effectively interfacing with Internet-based health programs and interventions.

The main finding of the study was that the positive rating of the Eat Healthy - Be Active portal was significantly predicted by fewer educated African American women with heavier weight perception and higher scores on WAB (i.e., they rated web features as more important). An implication of this specific finding is that education level was operating as a key factor in this study. As education level increased, positive website ratings decreased. Because the D.I.V.A.S. website is considered simple, and those who rated the portal more positively were less educated, it is important to have websites tailored for this group of African American women. The new portal apparently was better tailored to meet the needs and preferences of women with less education, making the portal more appealing to them. On the other hand, there appears to be a need for more advanced websites tailored to meet the needs of more educated African American women. Again, diversity among African American women as a group must be considered.

Another finding of the study was that the most important consideration when evaluating African American women's attitudes toward a weight loss website is that the site should be easy to read and have direct links to desired information. On the other hand, the least important attribute is having a talking voice. This result is 
consistent with other studies that focused on websites with topics other than weight loss (Cebi, 2013; Huang \& Benyoucef, 2013). These studies found that ease of use and ease of navigation to desired information are important to users. This finding is based on the ratings of people who are generally less educated, report themselves as being overweight, and gave higher ratings on website attributes and behavior (e.g., those who rated website features as more important).

In relation to the important aspects of a website for African American women, there was a significant positive correlation between high stage of change for accessing health care information, specifically sharing information with others (e.g., family, friends, students, clients), and high website attitudes and beliefs. There was also a significant positive correlation between high stage of change for accessing health care information and high website attitudes and beliefs. These positive correlations demonstrate that it is important to create websites that meet the needs of the target audience. It has been noted that women are critical to improving the health of those within their communities. Therefore, knowing that African American women are using the Internet to access health information may have implications for delivering and tailoring health messages. The significant positive relationship between a high stage of change (i.e., action, maintenance) for accessing health care information, specifically to share information with others, and high website attitudes and beliefs, demonstrates that although a website may be dedicated to the health of African American women, information relevant to the health of African American men and children can still be disseminated.

There were several methodological limitations to the study. The first limitation was that the convenience sample of volunteers with access to computers and the Internet may not be generalizable beyond this sample. Nevertheless, the population of focus in the study is appropriate because the target audience of the D.I.V.A.S. website is African American women. Additionally, conducting a study that requires Internet access creates many limitations. The recruitment of study participants was largely conducted through the Internet, as well as other technologies, such as text messages. As a result, the sample may not be representative of African American women who do not have Internet access.

Another limitation of the study is that current websites that focus on similar issues related to weight, nutrition, and physical activity are more advanced and possess more tools than the number of available tools on the pilot website used for this study. Therefore, this study is limited because it does not offer an assessment of the highest levels of technology and resources that are currently available for Internet-based weight loss interventions.

\section{Conclusion}

The findings of this study are important because as technology continues to advance, web developers may want to create websites that are complex. However, this study demonstrates that African American women are a diverse group; for those with lower levels of educational attainment, easy-to-read websites using simple navigation may work best - while not meeting the needs of African American women with higher levels of educational attainment. Therefore, it is important to design website content that is tailored to meet the needs of various categories of consumers. This study suggests that what was to be culturally-appropriate website content designed for African American women emerged as only being embraced by those women with lower levels of educational attainment. Thus, designers of website content must consider yet another level of complexity, namely, the diversity that arises from not only racial or cultural background, but also from the interplay of these factors with variables such as educational level of attainment.

Future research should further explore the role of these demographic variables (i.e., race, education), as well as others such as age, gender, professional attainment, and income in relation to preferences for website content. Future studies should also assess the attitudes and beliefs of African American women towards websites and social media interventions that utilize more advanced tools and strategies, given that they value ease of use of a website.

The elimination of health disparities will require a multi-faceted approach. African American women continue to suffer disproportionately higher rates of preventable illnesses. Understanding Internet preferences is necessary for the creation of effective web-based interventions. Therefore, being aware of the Internet preferences of this group will lead to the development of Internet-based wellness and weight loss programs with features tailored to African American women; these programs will also serve as public health tools for disseminating health information to their family members and perhaps to a larger community.

\section{Competing Interests Statements}

The authors declare that there are no competing or potential conflicts of interest. 


\section{References}

Adewuyi, E. O., \& Adefemi, K. (2016). Behavior change communication using social media: A review. International Journal of Communication and Health, 9, 109-116.

Bennett, G. G., Steinberg, D. M., Stoute, C., Lanpher, M., Lane, I., Askew, S., ... \& Baskin, M. L. (2014). Electronic Health (eHealth) interventions for weight management among racial/ethnic minority adults: A systematic review. Obesity Reviews, 15(S4), 146-158. https://doi.org/10.1111/obr.12218

Bleich, S. N., Bennett, W. L., Gudzune, K. A., \& Cooper, L. A. (2012). Impact of physician BMI on obesity care and beliefs. Obesity, 20(5), 999-1005. https://doi.org/10.1038/oby.2011.402

Bravender, T., Tulsky, J. A., Farrell, D., Alexander, S. C., Ostbye, T., Lyna, P., ... \& Pollak, K. I. (2013). Teen CHAT: Development and utilization of a web-based intervention to improve physician communication with adolescents about healthy weight. Patient Education and Counseling, 93(3), 525-531. https://doi.org/10.1016/j.pec.2013.08.017

Cancer Prevention Research Center. (2010). Detailed overview of the Transtheoretical Model. Retrieved from $\mathrm{http} / / / \mathrm{www} . u r i . e d u /$ research/cprc/transtheoretical.htm

Cavallo, D. N., Tate, D. F., Ries, A. V., Brown, J. D., DeVellis, R. F., \& Ammerman, A. S. (2012). A social media-based physical activity intervention: A randomized controlled trial. American Journal of Preventive Medicine, 43(5), 527-532. https://doi.org/10.1016/j.amepre.2012.07.019

Cebi, S. (2013). Determining importance degrees of website design parameters based on interactions and types of websites. Decision Support Systems, 54(2), 1030-1043.https://doi.org/10.1016/j.dss.2012.10.036

Glanz, K., Patterson, R. E., Kristal, A. R., DiClemente, C. C., Heimendinger, J., Linnan, L., \& McLerran, D. F. (1994). Stages of change in adopting healthy diets: Fat, fiber, and correlates of nutrient intake. Health Education and Behavior, 21(4), 499-519.

Huang, Z., \& Benyoucef, M. (2013). From e-commerce to social commerce: A close look at design features. Electronic Commerce Research and Applications, 12(4), 246-259. https://doi.org/10.1016/j.elerap.2012.12.003

Kirby, J. B., Liang, L., Chen, H. J., \& Wang, Y. (2012). Race, place, and obesity: The complex relationships among community racial/ethnic composition, individual race/ethnicity, and obesity in the United States. American Journal of Public Health, 102(8), 1572-1578. https://doi.org/10.2105/AJPH.2011.300452

Kodama, S., Saito, K., Tanaka, S., Horikawa, C., Fujiwara, K., Hirasawa, R., ... \& Sone, H. (2012). Effect of Web-based lifestyle modification on weight control: A meta-analysis. International Journal of Obesity, 36(5), 675-685. https://doi.org/10.1038/ijo.2011.121

Ling, S., \& Mengjun, R. (2013). The study on factors affecting online medicine purchase behavior based on TAM. Retrieved from http://www.seiofbluemountain.com/upload/product/201307/2013gjyx305a8.pdf

Mastellos, N., Gunn, L. H., Felix, L. M., Car, J., \& Majeed, A. (2014). Transtheoretical model stages of change for dietary and physical exercise modification in weight loss management for overweight and obese adults. Cochrane Database of Systematic Reviews, 2. https://doi.org/10.1002/14651858.CD008066.pub3

Norcross, J. C., Krebs, P. M., \& Prochaska, J. O. (2011). Stages of change. Journal of Clinical Psychology, 67(2), 143-154. https://doi.org/10.1002/jclp.20758

Ogden, C. L., Carroll, M. D., Kit, B. K., \& Flegal, K. M. (2014). Prevalence of childhood and adult obesity in the United States, 2011-2012. Journal of the American Medical Association, 311(8), 806-814. https://doi.org/10.1001/jama.2014.732

Patrick, K., Calfas, K. J., Norman, G. J., Rosenberg, D., Zabinski, M. F., Sallis, J. F., ... \& Dillon, L. W. (2011). Outcomes of a 12-month web-based intervention for overweight and obese men. Annals of Behavioral Medicine, 42(3), 391-401. https://doi.org/10.1007/s12160-011-9296-7

Pew Research Center. (2017). Social media fact sheet. Retrieved from http://www.pewinternet.org/fact-sheet/social-media/

Sira, N., \& Pawlak, R. (2010). Prevalence of overweight and obesity, and dieting attitudes among Caucasian and African American college students in Eastern North Carolina: A cross-sectional survey. Nutrition Research and Practice, 4(1), 36-42. https://doi.org/10.4162/nrp.2010.4.1.36

Skranes, L. P., Løhaugen, G. C., \& Skranes, J. (2015). A child health information website developed by physicians: 
The impact of use on perceived parental anxiety and competence of Norwegian mothers. Journal of Public Health, 23(2), 77-85. https://doi.org/10.1007/s10389-015-0659-6

Springvloet, L., Lechner, L., de Vries, H., Candel, M. J., \& Oenema, A. (2015). Short-and medium-term efficacy of a web-based computer-tailored nutrition education intervention for adults including cognitive and environmental feedback: Randomized controlled trial. Journal of Medical Internet Research, 17(1). https://doi.org/10.2196/jmir.3837

Tate, D. F., Wing, R. R., \& Winett, R. A. (2001). Using Internet technology to deliver a behavioral weight loss program. Journal of the American Medical Association, 285, 1172-1177. https://doi.org/10.1001/jama.285.9.1172

Tavakol, M., \& Dennick, R. (2011). Making sense of Cronbach's alpha. International Journal of Medical Education, 2, 53-55. https://doi.org/10.5116/ijme.4dfb.8dfd

Tettey, N. S. (2010). An online evaluation of a new web-based source of information on eating healthy and being active designed for African American women: exploring relationships among personal-level variables and website ratings (Doctoral dissertation). Teachers College, Columbia University, New York, NY.

U.S. Department of Health and Human Services. (2010). The obesity crisis in America. Retrieved from http://www.surgeongeneral.gov/news/testimony/obesity07162003.html.

U.S. Department of Health and Human Services. (2015). About healthy people. Retrieved From: https://www.healthypeople.gov/2020/About-Healthy-People

West, J. H., Hall, P. C., Arredondo, V., Berrett, B., Guerra, B., \& Farrell, J. (2013). Health behavior theories in diet apps. Journal of Consumer Health on the Internet, 17(1), 10-24. https://doi.org/10.1080/15398285.2013.756343

Wilson, D. K., Alia, K. A., Kitzman-Ulrich, H., \& Resnicow, K. (2014). A pilot study of the effects of a tailored web-based intervention on promoting fruit and vegetable intake in African American families. Childhood Obesity, 10(1), 77-84. https://doi.org/10.1089/chi.2013.0070

Wright, S. M., \& Aronne, L. J. (2012). Causes of obesity. Abdominal Imaging, 37(5), 730-732. https://doi.org/10.1007/s00261-012-9862-x

\section{Copyrights}

Copyright for this article is retained by the author(s), with first publication rights granted to the journal.

This is an open-access article distributed under the terms and conditions of the Creative Commons Attribution license (http://creativecommons.org/licenses/by/4.0/). 